\title{
Formação ajustada: sobre a capitalização do humano na formação \\ e sua administração total ${ }^{1}$
}

Adjusted training: on human capitalization in training and its total management

Dirk Stederoth $^{*}$

\section{Resumo}

Partindo da análise das rápidas reformas da educação na Alemanha desde a virada do milênio, este artigo volta-se, inicialmente, para o período anterior a essas reformas, mostrando que elas são consequências da política educacional da Organization for Economic Co-operation and Development (OECD), que, desde a década de 1950, tem se esforçado para harmonizar, dentre outros aspectos, os sistemas educacionais com a formação do capital humano. Este texto demonstra que a formação do capital humano está na base dos processos de padronização das reformas atuais, e que a ideia de gerenciamento total dos recursos humanos é o objetivo principal dessas reformas. Isso resulta em uma visão do ser humano reduzida aos requisitos econômicos predeterminados. Por fim, destaca-se, com base em Herbert Marcuse, a relevância do conteúdo educacional estético, emocional, não mensurável, como referência contrária à visão reducionista da formação para o mercado.

Palavras-chave: Bildung. Capital humano. Reforma de ensino na Alemanha. Marcuse.

\section{Abstract}

Starting from the analysis of the rapid reforms of education in Germany since the turn of the millennium, the article focus first on the previous period of these reforms, showing that they are consequences of the educational policy of the Organization for Economic Co-operation and Development (OECD), which since the fifties, has endeavored to harmonize, among other aspects, educational systems with the formation of human capital. The text demonstrates that the formation of human capital is based on the standardization processes of the current reforms and that the idea of total human resources management is the main goal of these reforms. This results in a view of the human being who is reduced to pre-determined economic requirements. In the end, the author emphasizes, based on Herbert Marcuse, the relevance of the aesthetic, emotional, non-measurable educational content, as a counterpoint to the reductionist view of training for the market.

Keywords: Bildung. Human capital. Marcuse. Reform of education in Germany.

Recebido em: 26/02/2017 - Aprovado em: 05/07/2017

http://dx.doi.org/10.5335/rep.v24i3.7761

* Doutor e livre-docente em Filosofia pela Universidade de Kassel, Alemanha. Professor da Universidade de Kassel. E-mail: d.stederoth@uni-kassel.de 


\section{Introdução}

Nos últimos vinte anos, nosso sistema de formação vem sofrendo uma das transformações mais profundas na sua história, pois suas intervenções são estampadas por uma sistemática pouco imaginável devido à sua amplitude. Como uma rede que se autodesdobra, as estruturas dessa reforma alcançam os últimos cantos do setor educativo, estabelecendo, neles, uma facticidade aparentemente inevitável. Quem quiser opor-se a essa facticidade será acusado, de imediato, de negar os fatos. É esse ajuste, essa conformidade como que miraculosa, que é responsável pela construção rasante deste edifício novo, no qual a crítica em relação a um piso pronto já se perde no solo do recém-construído.

Ao primeiro olhar, o edifício novo da formação, sistematicamente erguido, parece ser pouco problemático, pois já no início da construção foi diagnosticado um acúmulo de destroços referente à definição científica do conceito de formação, quando Heinz-Elmar Tenorth falou, no seu inventário, que o conceito de formação estaria sendo "usado de modo quase inflacionário" (1997, p. 970, tradução de Hans-Georg Flickinger), constatando-se "uma heteronomia imensa de interpretações" (1997, p. 971, grifo do autor) em relação a esse conceito. Assim, a homogeneidade construída parece ser nada menos do que um golpe de liberação para o terreno de formação que, orientado por critérios de eficiência claramente legitimáveis e empiricamente fundados, pode expor-se finalmente à comparação internacional. Resta, porém, a dúvida se o fundamento de tal edifício novo se iguala àquela torre famosa, cuja cidade tinha de emprestar o nome para 0 sinal de partida desse processo: Programme for International Student Assessment (Pisa).

No intuito de esclarecer até que ponto esse edifício novo de formação foi construído num fundamento erosivo, seu desenvolvimento será investigado em quatro passos: primeiro, no que se refere aos fundos históricos do conceito capital humano; segundo, com relação à sua fixação pela definição de diretrizes de formação; terceiro, com foco na sua realização mediante uma administração total; e quarto, finalmente, no que diz respeito às consequências para quem está sendo atingido de modo mais imediato: os seres humanos.

\section{De Sputnic até Pisa - um dimensionamento histórico}

Como já indicado, costuma-se contar com o estudo comparativo chamado Pisa, encomendado ao fim dos anos 1990 pela Organization for European Economic Co-operation (OECD), como início da construção desse edifício novo; um estudo que, 
nessa forma, de fato foi uma novidade, pois pela primeira vez os sistemas educativos de 28 países membros da OECD (e mais outros quatro) foram submetidos a uma comparação empírica. ${ }^{2}$ Porém, com um olhar mais atento, evidencia-se que o pano de fundo desse estudo remonta aos últimos anos da década de 1950, pois o assim chamado "choque de Pisa" funda-se, em última instância, no "Choque de Sputnic" e nas reações a este.

Como Daniel Tröhler (2013) recentemente destacou, ${ }^{3}$ as reações dos Estados Unidos da América ao Choque de Sputnic não consistiam apenas na fundação da Nasa, se não, além disso, numa ofensiva na educação, expressa no National Defense Education Act (NDEA), votado no dia 02 de setembro de 1958. ${ }^{4}$ Essa ofensiva, apoiada em fortes investimentos financeiros, viveu sua continuação internacional na fundação de um comitê da OECD (Committee for Scientific and Tecnical Personnel - CSTP), entre cujas tarefas mais importantes constava a do desenvolvimento industrial dos Estados do sul da Europa, com sua tradicional orientação mais agrícola. O respectivo projeto, o Mediterranean Regional Project (MRP), tornou claro, além do aumento dos membros, o que na verdade foi visto como a passagem, realizada em 1960, da Organization for European Economic Co-operation (OEEC) para a Organization for Economic Co-operation and Development (OECD). Como Tröhler mostra, “[...] 'development' não foi pensado simplesmente como continuação progressiva de algo existente [...], se não como acomodação a um único modelo a ser perseguido. [...] $\mathrm{O}$ veículo foi a ampliação e transformação do sistema educacional segundo as diretrizes da OECD" (TRÖHLER, 2013, p. 64, grifo do autor).

De modo rígido, essa transformação foi imposta pela OECD mediante a formação de planejadores nacionais de educação à base de programas de instrução, nos quais os participantes deveriam ajustar-se a uma só estratégia. ${ }^{5}$ Essa via de influenciar indiretamente o desenvolvimento nacional no campo educativo mostrou seus frutos não apenas nas reformas do sistema educacional dos anos 1970 na República Federativa Alemã, se não, e antes de tudo, na transformação do campo educativo em nosso tempo, iniciada pelo choque de Pisa. ${ }^{6}$

Ora, em que consistia a teoria de formação da OECD, segundo a qual os sistemas de educação nacionais deveriam ser ajustados? São elucidativas, a esse respeito, as contribuições de uma conferência da OECD: "Policy Conference on Economic Growth and Investment in Education", ocorrida entre 16 e 20 de outubro de 1961, em Washington, pois essas contribuições dão uma primeira prova ${ }^{7}$ do estreitamento, hoje amplamente realizado, da teoria de formação e da teoria do capital humano, ${ }^{8}$ algo expresso claramente na seguinte passagem: 
Hoje é natural que o campo educativo pertença ao complexo da economia, sendo que é necessário preparar os seres humanos para a economia de mesmo modo como bens materiais e máquinas. O campo educativo tem o mesmo valor como autoestradas, mercearias e fábricas de fertilizantes. Sem corar e com boa consciência econômica, podemos afirmar agora que a importância da acumulação de capital intelectual é comparável - e talvez superior a longo prazo - à acumulação de capital real (BRINGOLF et al., 1966, p. 40). ${ }^{9}$

Em concordância com os princípios da teoria do capital humano, o "capital intelectual" vê-se equiparado ao "capital real" (portanto, a autoestradas, mercearias, etc.) e revestido de cálculo econômico. Diante desse fundo de equiparação, não são apenas os educadores que aparecem numa luz diferente ao se falar de sua categoria como "professor fator produtivo" e dos alunos como "material bruto" (BRINGOLF et al., 1966, p. 44-45), é também o conceito de formação que se vê reconsiderado, nesse contexto, com vistas ao uso econômico flexível:

O próprio conceito de formação geral exige uma definição nova. [...] Com a formação geral deve ser visada a capacidade de adaptação continuada, do manejo racional de situações novas e de criação de esquemas flexíveis de pensamento para todas as grandes áreas científicas (BRINGOLF et al., 1966, p. 37).

Nos debates atuais - que serão tematizados mais adiante -, a proximidade dessa definição nova para com a orientação pragmática do conceito de competência não é o único fator que comprova a atualidade desses primeiros documentos da OECD. Outro elemento importante da capitalização humana na formação está no levantamento estatístico dos parâmetros calculáveis do capital formativo, possibilitando, assim, a inclusão completa do campo educativo num balanço econômico geral:

O planejamento da educação deveria tornar-se parte integral de cada política econômica nacional. [...] Precisa ser vista como uma das primeiras e mais urgentes tarefas do planejamento educativo a elaboração de um sistema orientador de cifras estatísticas estandardizadas, tal como a economia nacional o fez para comparar o desenvolvimento econômico com os gastos do Estado (BRINGOLF et al., 1966, p. 64).

Salta aos olhos que a enormidade de números do Education at a Glance OECD Indicators ${ }^{10}$ publicado anualmente, representa a realização internacional dessa demanda por um estandardizado sistema estatístico orientador.

Diante desse fundo, o Pisa e a atual reconstrução do campo educacional significam apenas a realização consequente de um plano elaborado devido ao Choque de Sputnic, passo a passo implementado, ao longo de anos, nos sistemas nacionais de educação. Como não é possível reconstruir, neste texto, todo esse desenvolvimento, nas suas diferentes etapas, destaca-se apenas um marco que influenciava enormemente o campo da educação alemão dos anos 1970 e 1980: o Plano de Estrutura para o Campo Educativo (Strukturplan für das Bildungswesen), elaborado e votado pelo Conselho Alemão de Educação (DEUTSCHER BILDUNGSRAT, 1970). 
Esse documento volumoso apresenta uma perspectiva de planejamento abrangente, que, desde o conceito de aprendizagem e passando pelo currículo e pelo desenvolvimento dos tipos de escola, inclui a formação de professores e a administração e o financiamento da educação. Em oposição explícita à tradição da pedagogia vinculada às ciências do espírito, os objetivos da educação escolar foram mais orientados em direção às respectivas qualificações exigidas pela sociedade, sendo que a reivindicação por uma aprendizagem cientificamente sustentada e, portanto, continuada implicava a demanda reforçada por um aprender do aprender. ${ }^{11}$

No foco dessas demandas, constava a pretensão de preparar os alunos e os adultos para as exigências flexíveis do desenvolvimento tecnológico, social e econômico; um desenvolvimento do qual eles só poderiam dar conta adaptando-se, de modo permanente, mediante a própria qualificação continuada.

À determinação cientificista da aprendizagem corresponde, formalmente, o princípio do apreender a apreender. Os currículos mediatizam não apenas conhecimentos e habilidades, mas também a capacidade de apreender sempre de novo [...] A promoção específica da capacidade de apreender [...] está sendo exigida também pelo andamento do desenvolvimento social, técnico-científico e econômico, assim como pelas mudanças das condições de vida e das relações de trabalho. As transformações tornam necessária a formação continuada, podendo até acordar a vontade de apreender permanentemente; algo, porém, que precisa ter sido aprendido antes (DEUTSCHER BILDUNGSRAT, 1970, p. 33).

Essa reivindicação de uma autoadaptação "prazerosa” a desenvolvimentos sociais, dirigida, no seu cerne, a uma autônoma qualificação profissional continuada, cumpre, desse modo e ao fundo, um estreitamento de formação geral e formação profissional, em conformidade com as ideias da OECD; fato esse já apontado por Heydorn, na sua crítica ao Plano de estrutura: "Por meio da cientificidade do processo de aprendizagem, a contradição entre formação geral e formação profissional está sendo suspensa mediante o método" (HEYDORN, 1972, p. 92).

Encontraremos esse estreitamento ainda no decorrer de considerações posteriores, por ocasião da definição atual do conceito de competência. No entanto, dois aspectos do Plano de estrutura, que também nos preocuparão ainda, não podem ser detalhados aqui: a concatenação da reforma da formação com a reforma da estrutura administrativa ${ }^{12}$ e a demanda por um planejamento educativo, baseado em dados empíricos (DEUTSCHER BILDUNGSRAT, 1970, p. 270).

É possível constatar diversas continuidades entre as tendências originais da OECD de reformar a educação e o Plano de estrutura: a saber, a orientação da formação em vista de demandas sociais, econômicas e técnicas; um estreitamento de formação geral e capacidade de adaptação profissional flexível; a demanda por um planejamento baseado em dados e uma administração que condiz a ele. Nesse sentido, pode-se observar, com Lederer, que o Plano de estrutura: 
[...] [marca] afinal o início de uma "economização da formação" que, até hoje, vem se agravando fortemente; economização essa, entendida como direcionamento sobretudo instrumental-funcional para os objetivos profissionais e micro e macroeconômicos, que visam tanto ao entendimento do próprio conceito de formação quanto à definição das tarefas das instituições do sistema educativo e de suas formas organizacionais (LEDERER, 2015, p. 312).

Até que ponto é possível falar, hoje, do agravamento dessa tendência? Essa questão será investigada junto com um documento que poderia obter uma importância para a atual reforma da educação, semelhante à importância do Plano de estrutura para os anos 1970 e 1980: a perícia Sobre o desenvolvimento de diretrizes nacionais de educação, apresentada em 2003 e publicada em 2007 (KLIEME et al., 2007).

\section{Diretrizes de educação como base da formação estandardizada}

O motivo para a perícia, encomendada em 2002 pelo Ministério de Educação alemão (Bundesministerium für Bildung und Forschung - BMBF), foi a má figura feita pelas escolas alemãs nas pesquisas comparativas internacionais do Trends in International Mathematics and Science Study (TIMSS) e no PISA, assim como as diretrizes de educação, definidas em algumas disciplinas - já em 2002 - como reação da Conferência dos Ministros de Cultura (KMK) a esses estudos. A tarefa dessa perícia consistia, portanto, em:

[...] esclarecer a concepção das diretrizes educativas em termos disciplinares e apresentar uma concepção do marco geral do modo de como demarcar diretrizes educativas para o sistema escolar alemão, isto é, de como poder desenvolvê-las e aplicá-las. Nisso deveria ser levado em consideração o debate internacional sobre as políticas e ciências educativas (KLIEME et al., 2007, p. 14).

Se olharmos para a definição do conceito "diretriz" na perícia, querendo saber a qual debate da ciência educativa ela se refere, somos levados (depois da apresentação do uso de diretrizes na Grã-Bretanha), inequivocamente, a uma fonte que, diante do pano de fundo já explicado, é bastante interessante: trata-se "do texto muito influente "Escola e Qualidade" (KLIEME et al., 2007, p. 32), que representa um relatório internacional da OECD, de 1991 (o original foi publicado em 1989).

Das três exigências formuladas nesse relatório a respeito das diretrizes, as duas primeiras são particularmente esclarecedoras:

a) em nível da sociedade como um todo, deveria ser iniciado um processo geral da reavaliação e precisão de objetivos e ideias pedagógicos valorativos, fundamentando-se as diretrizes nisso. [...]; b) deveriam ser elaborados informações estatísticas e indicadores que permitissem, na medida possível, um debate verdadeiro sobre questões geralmente reconhecidas. [...] a) e b) andam de mãos dadas reforçando-se mutuamente (OECD, 1991, p. 68). 
Para deixar essa concatenação mais uma vez bem clara: o "[...] processo da reavaliação e precisão de objetivos pedagógicos e ideias valorativas em nível da sociedade como um todo" (OECD, 1991, p. 68) é aquele, portanto, no qual as diretrizes educacionais deveriam basear-se. Esse processo, porém, deveria andar de mãos dadas com "informações estatísticas e indicadores" que permitissem "um debate verdadeiro" sobre essas questões gerais. O que aí já se anuncia é a tendência, hoje reforçada, de querer fundamentar as diretrizes educacionais unicamente em conhecimentos estatísticos, com as linhas orientadoras desses indicadores estatísticos tendo que seguir as normas internacionais; algo que fica claramente expresso no relatório da OECD sob o título "Avaliação do sistema completo":

Precisa-se de indicadores econômicos para documentar a efetividade dos gastos; mais importante ainda são indicadores de qualidade. Alguns acreditam ser muito importante receber os dados nacionais por meio dos diversos componentes de qualidade, de preferência numa forma que facilite uma comparação internacional (OECD, 1991, p. 145).

Que esses "alguns" se impuseram finalmente é documentado não apenas pelo estudo Pisa, mas também pelo relatório estatístico já mencionado, Education at a Glance: (2000-2015) OECD Indicators.

A concatenação entre essas tendências e a perícia Zur Entwicklung nationaler Bildungsstandards (Sobre o desenvolvimento de normas nacionais de educação) evidencia-se quando olhamos mais de perto para sua definição geral de diretrizes. Essa definição geral reza:

Diretrizes educacionais, tal como concebidas nessa perícia, remetem a objetivos gerais da formação. Elas denominam as competências a serem passadas pela escola aos alunos e alunas, para que se atinja determinados objetivos centrais da formação. As diretrizes educacionais definem quais competências deveriam ser atingidas pelas crianças e pelos adolescentes nas determinadas classes. As competências são descritas de modo tão concreto, que possam ser convertidas em tarefas e colhidas por meio de procedimentos de teste (KLIEME et al., 2007, p. 19, grifos dos autores).

À primeira vista, isso parece ser uma forma típica de um procedimento científico, pois se definem, inicialmente, os fins gerais, que, em seguida, são concretizados em competências específicas, para, depois, ser controlada a realização dos objetivos gerais via procedimentos de teste que visam, especificamente, à competência. Se levarmos em consideração também o fato de que, entre os objetivos gerais de educação, “[...] a imagem da individualidade é vista como guia, no qual [...] a dignidade do ser humano e o livre desenvolvimento da personalidade são tidas como máximas" (KLIEME et al., 2007, p. 63), parece ser necessário aceitar a avaliação da perícia de que competências "[...] não descrevem outra coisa a não ser tais ha- 
bilidades dos sujeitos, visadas e pressupostas também pelo conceito de formação" (KLIEME et al., 2007, p. 65). ${ }^{13}$

No entanto, o olhar mais atento ensina-nos algo mais, pois essa definição deve ser lida diante do pano de fundo da consequente "orientação pelo output", tida como princípio pela perícia (KLIEME et al., 2007, p. 12). Por isso, temos de nos perguntar em que medida aqueles objetivos nobres da formação deixam-se operacionalizar em competências como objetos de teste. Quando a perícia constata, em concordância com sua orientação pelo output, que, "[...] sem controle dos resultados, os objetivos de formação enquanto fatores estatísticos ficariam desacoplados do desenvolvimento verdadeiro da escola" (KLIEME et al., 2007, p. 24), podemos perguntar - diante do fundo da necessária operacionalização dos objetivos gerais de formação -, pelo lado inverso, se esses objetivos não se veem desacoplados do desenvolvimento escolar exatamente devido a esse foco nos procedimentos de teste; pois elementos essenciais desses objetivos talvez se esquivem totalmente da operacionalização em testes. Então, investiguemos essa questão com relação à instância mediadora entre objetivos gerais de formação e procedimentos de teste, isto é, entre as competências e os modelos de competência.

A perícia apoia-se num conceito de competência definido em 2001 por Franz E. Weinert, num artigo geral sobre a medição do rendimento nas escolas. Por competências, ele entende:

[...] as capacidades e habilidades cognitivas disponíveis aos indivíduos ou possíveis de serem apreendidas por meio delas, a fim de resolver determinados problemas; e, junto a isso, disposições e potenciais motivacionais, volitivos e sociais, para usar as soluções de problemas em situações variáveis com sucesso e responsabilidade (WEINERT, 2001, p. 2). ${ }^{14}$

Essa definição é interessante em diversas perspectivas. Em primeiro lugar, salta aos olhos a focagem desse conceito de competência em "solucionar problemas". ${ }^{15} \mathrm{O}$ fato não interessa apenas por se tratar do manejo de problemas - o que poderia ser suficiente numa generalização forte do conceito de problema -; ora, a focagem na solução de problemas anuncia, de imediato, a subsunção desse conceito de competência à modelagem do teste. Para aguçar mais ainda essa crítica, poderíamos dizer que um homem maior se destacaria menos pela reação a complexas situações problemáticas com soluções precoces, se não por ter aprendido, com demasiada frequência, a enfrentá-las como situações problemáticas na sua contraditoriedade, para não evocar, com soluções precoces, situações ainda piores. Uma focagem na capacidade de solucionar problemas reduz a competência a aspectos formais da vida que, na sua univocidade apenas aparente, levam a soluções unívocas, de modo que os elementos não formalmente concebidos da vida - que apresen- 
tam o elemento essencial nas relações sociais, políticas e individuais - caem para fora desse conceito de competência.

Um segundo aspecto importante desse conceito de competência consiste no fato de que ele contém dois componentes principais. O primeiro refere-se a "disposições e habilidades" puramente "cognitivas", já o segundo refere-se àquelas "motivacionais, volitivas e sociais". Enquanto Weinert ainda não aplicava uma gradação entre os dois componentes, a perícia colocava a competência cognitiva no primeiro plano, exatamente devido à operacionalidade da competência (KLIEME et al., 2007, p. 72). ${ }^{16}$ Se acompanharmos o desenvolvimento da concepção de competência posterior à perícia, percebe-se que o programa principal da Deutsche Forschungsgemeinschaft (DFG), "Modelos de competência para o recolhimento de resultados individuais de aprendizagem e para fazer saldo de processos educacionais", dirigido por Eckhard Klieme e Detlev Leutner com prazo de 2007 a 2013, vem operando, desde o início, com um conceito de competência puramente cognitivo: "Para o SPP (programa principal - D.S.), definimos competências como disposições cognitivas de trabalho em contextos específicos, que, em termos funcionais, se referem a situações e exigências em determinados domínios" (KLIEME; LEUTNER, 2006, p. 879, grifo dos autores). ${ }^{17}$ Do mesmo modo, o programa de pesquisa Modelagem e Colhimento de Competência no Setor Universitário (KoKoHs) (prazo: de 2011 a 2015), ricamente equipado pelo BMBF com setenta projetos particulares, remete ao conceito de competência de Weinert; porém, remete-se, também neste caso, apenas ao componente cognitivo. ${ }^{18}$

Se tomarmos esses dois grandes programas como exemplos para o desenvolvimento do conceito de competência, poder-se-á constatar que, quanto à equivalência dos dois componentes ainda defendidos por Weinert, as exigências da operacionalidade do conceito de competência levavam a uma sua divisão ao meio, pois as "disposições e habilidades motivacionais, volitivas e sociais" não são mais levadas em consideração, devido à impossibilidade de submetê-las ao teste. Na retrospectiva em relação ao já mencionado programa principal da DFG, Detlev Leutner tenta, afinal, excluir completamente esse componente do foco, ao supor que "[...] no momento em que competências estão sendo concebidas mediante testes, mensuram-se, implicitamente e junto aos elementos cognitivos, também elementos afetivos" $\left(2014\right.$, p. 391). ${ }^{19}$ Já em 2000, na reação imediata à pesquisa Pisa e ao conceito de literacy que lhe subjaz, Rudolf Messner (2000) advertiu que esse conceito não incluiria, de modo algum, a dimensão estética e emocional da leitura, se não apenas seu aspecto cognitivo; a investida de Leutner, porém, degrada essa dimensão a um aspecto meramente implícito. 
Então, o que significa isso? Se tomarmos a perícia de Klieme a sério, os procedimentos de teste servem - como já dito - para examinar os objetivos gerais da educação. Ora, se relacionarmos esses objetivos educativos à redução atual do conceito de competência, dada pela sua operacionalização, surgirão duas possibilidades: ou a atual pesquisa educacional afirma seriamente que para um indivíduo, para o qual "dignidade humana e livre desenvolvimento da personalidade" valem como "máximas últimas", as "disposições e habilidades motivacionais, volitivas e sociais" são aspectos apenas implícitos - o que, diga-se de passagem, parece ser grotesco; ou com a operacionalização do conceito de competência para os testes introduziu-se, como que por contrabando - mais inconsciente do que conscientemente -, um novo objetivo-guia de educação; algo que terá de ser explicado. É isso que tentamos fazer em seguida.

\section{Administração total como ideia educacional abrangente}

Um candidato relativamente óbvio para uma ideia educacional de fundo é a economia, ou seja, a produção de capital humano. A esse respeito, o relatório da OECD Education at a Glance (2008) formula abertamente qual foco principal deveria ser imposto: "Uma tarefa principal dos sistemas educativos consiste em providenciar ao mercado de trabalho tantas e tão diferenciadas competências quantas os empresários precisam" (2008, p. 31). Além disso - e embora de origens diferentes na economia e no discurso de formação -, os conceitos de capital humano e de competência revelam essenciais "afinidades eletivas" - o que foi sublinhado por Jörg Nicht e Thomas Müller (2009).$^{20}$ Tendo-se presente que o Ministério Federal de Educação e Pesquisa (BMFT) não está apoiando somente grandes programas com foco no desenvolvimento de modelos de competência, mas, igualmente, workshops sobre "Educação como bem de investimento" (BMBF, 2004), reforça-se o fato de os indicadores sobre "a dignidade humana e o desenvolvimento livre da personalidade" não serem o objetivo principal da educação, se não o abastecimento mais ajustado possível das empresas com o respectivo capital humano. Isso se evidencia também na saudação do representante do BMFT, Herbert Diehl, por ocasião do mencionado workshop:

Todos nós sabemos: a reivindicação de Lisboa de transformar a Europa no espaço econômico e científico mais apto a concorrer em nível mundial só poderá ser cumprida se colocarmos os recursos humanos, hoje e futuramente necessários, à disposição para o desenvolvimento de nossas economia e sociedade (BMBF, 2004, p. 3).

O florear do espaço econômico europeu depende, portanto, da disponibilidade do recurso humano, tendo o sistema educativo a tarefa de entregar esse recurso de forma ajustada. Tal entrega acontece em forma de competências cognitivas adequadas, cara- 
terizadas na perícia de Klieme et al. como: "memória disciplinar, conhecimento abrangente, habilidades automatizadas" (KLIEME et al., 2007, p. 72). São essas competências imediatamente úteis, cuja produção é visada pelo sistema educacional, fazendo-se, assim, da produção do capital humano ajustado o objetivo mais nobre da formação.

Entretanto, o ajuste adequado representa ainda um problema seríssimo. Segundo o relatório da OECD Education at a Glance (2008), as competências, ou o capital humano, ainda são muito pouco estandardizadas em termos de comparação internacional. ${ }^{21}$ Para enfrentar esse déficit de estandardização, os autores do relatório recorrem à "Classificação estandardizada das profissões (Isco)" ${ }^{22}$ que, junto aos "Isco-Skill-Levels", isto é, junto aos perfis exigidos para as diferentes áreas profissionais, poderia servir como matriz perfeita para a estandardização da demanda por e o abastecimento com o capital humano, supondo-se que todas as economias nacionais aderissem a ela. ${ }^{23}$

A ideia implicada não é apenas a satisfação geral das demandas sociais e econômicas, se não a contabilidade empresarial ${ }^{24} \mathrm{e}$ a administração sistemática do recurso humano. Ora, a direção visada é a realização abrangente e sistematicamente estruturada dos antigos planos da política de formação da OECD, tal como foram apresentados no primeiro parágrafo. Trata-se da estandardização da medida contábil "demanda" por meio do ajustamento tendencial dos tipos profissionais e das estruturas por eles exigidas; este ajustamento, por sua vez, precisa ser acompanhado pela respectiva estandardização da medida contábil "recurso", ou seja, dos produtos para a satisfação das demandas (capital humano), para que ambas as quantidades possam ser compensadas uma com a outra. A "empresa" responsável pela produção desses produtos é o sistema educativo nas suas modalidades nacionais, isto é, os departamentos e as dependências dessa empresa, cuja qualidade na produção precisa ser contínua e comparativamente controlada. Servirão a isso os procedimentos de teste, os relatórios e estudos comparativos internacionais que, no caso ideal, deveriam orientar-se pelas normas mencionadas.

Diante desse cenário alimentado pelas referidas tendências atuais da pesquisa e da economia educacionais, é possível definir, então, a perspectiva real do objetivo das diretrizes educativas; uma perspectiva que se destaca menos pela "dignidade humana" ou pelo "livre desenvolvimento da personalidade", do que pela total administração empresarial do capital humano com todos seus componentes, tais como levantamento da demanda, contabilidade dos recursos, controle, etc.

Um sistema educativo assim ajustado às estruturas econômicas tem consequências diretas para o modelo e o dia a dia de nossos estabelecimentos educativos, na medida em que eles assumem, passo a passo, o caráter empresarial. Foi Heinz Bude quem descreveu esse desenvolvimento referente à escola como uma passagem de instituições educacionais para organizações educativas; algo que influencia fortemente o caráter dos estabelecimentos educativos: 
Organizações são julgadas segundo seu output mediante números a serem alcançados, ao passo que instituições são julgadas segundo a concordância com seu sentido. [...] Se tratarmos instituições como organizações, muda o modo da autorização do conhecimento. Neste caso, não têm mais aqueles a última palavra, que conhecem a tradição trabalhando no próprio lugar, se não aqueles que interpretam os testes ou controlam, via computador, os índices (BUDE, 2011, p. 113). ${ }^{25}$

Desde a reforma de Bologna, tal mudança também pode ser observada, sobretudo, no desenvolvimento das universidades; uma reforma que é caraterizada pelo crescimento inflacionário de estruturas burocráticas e de gestão. ${ }^{26}$ Seria exagerado investigar, aqui, a mata espessa de estruturas administrativas de exames, a influência das agências privadas de credenciamento, o crescimento exponencial de relatórios e de medidas para segurar a qualidade, a aquisição de recursos externos e a gestão desses recursos (para lembrar somente umas poucas áreas respectivas) - certo é, porém, que esse desenvolvimento ainda não ultrapassou seu auge, já que está faltando ainda um balanço sistemático de competências individuais nas universidades, preparado pelo KoKoHs. De mesmo modo, há de se esperar um crescimento da burocracia com dinâmica própria, a partir do momento em que o "European Credit Transfer and Accumulation System" (ECTS), introduzido para organizar o tempo de estudos, for usado também como base de cálculo em relação ao orçamento das faculdades - como já acontece no caso da Universidade de Amsterdam $^{27}$-, ou quando for introduzido um sistema comparável para calcular o rendimento do ensino, isto é, um "European Teaching Load and Accumulation System" (Etlas). ${ }^{28}$ Quanto à modelagem empresarial das universidades, pode-se verificar ainda poucas lacunas ou espaços livres, que poderão ser fechados sob o pretexto da eficácia.

Porém, são não apenas os estabelecimentos educacionais atingidos por esse desenvolvimento, mas também, e sobretudo, aqueles que deveriam ser formados nesses estabelecimentos, assim como aqueles que mediatizam tal formação - em resumo: os seres humanos enquanto professores e alunos. Num parágrafo final será tematizado, mais de perto, até que ponto tal educação ajustada exerce influência no nosso entendimento do ser humano.

\section{Formação ajustada e o ser humano conforme a medida}

Herbert Marcuse pode ser considerado o representante da teoria crítica que, no seu escrito $O$ homem unidimensional, destacou do modo mais abrangente possível as estruturas da economização da vida pública e privada, assim como "a sua administração total". Com seu conceito de unidimensionalidade, ele descreve o ni- 
velamento sistemático da contradição entre existência individual e social; fato pelo qual uma sociedade se transformaria em algo totalitário:

Nessa sociedade, o aparato de produção tende a tornar-se totalitário na medida em que ele determina não apenas as atividades, habilidades e posturas socialmente necessárias, mas também as necessidades e os desejos individuais. Ele nivela, assim, a oposição entre existência privada e pública, entre necessidades individuais e sociais. Assim, ele aplana a oposição entre existência privada e pública, entre necessidades individuais e sociais (MARCUSE, 1970, p. 17). ${ }^{29}$

Com recurso à psicanálise e sua revelação da plasticidade e da formação de necessidades condicionadas pela socialização, Marcuse expõe o mecanismo que cria esse aplainamento. No capítulo "A vitória sobre a consciência infeliz: dessublimação repressiva", Marcuse (1970, p. 76-102) mostra o modo como necessidades socialmente conformes são estampadas já na primeira infância, não precisando mais, nessa forma reduzida, de nenhuma sublimação em necessidades sociais, porque desde o início já são formadas em conformidade com a sociedade. Sem poder aprofundar isso neste contexto, pergunta-se, no entanto, até que ponto essa estrutura, que serve para explicar a "euforia na desgraça" (MARCUSE, 1970, p. 25) de sociedades pós-industriais de consumo, pode ser transferida ao tema presente. Ao pressupor, desde a primeira frase da Metafísica de Aristóteles e de modo como que natural, que a busca por saber ou formação representa uma constante antropológica, poder-se-á perguntar, com todo direito e com base nas análises de Marcuse, se essa busca pela formação não é também suscetível a uma plasticidade, podendo ser submissa, portanto, a um arranjo socialmente estampado.

Tendo-se em vista que o Estado de Hessen editou (igual a outros Estados), no ano 2007, um "Plano de formação e educação para crianças entre 0 e 10 anos", com o título afirmativo "Formação desde o início" (KULTUS und SOZIALMINISTERIUM, 2012), vemo-nos levados diretamente à introdução de programas educativos para jardins de infância e creches, dirigidos a competências; programas esses que apontam para currículos escolares relevantes e, em última instância, para o mercado de trabalho. ${ }^{30}$ Uma vez espalhadas as estruturas mencionadas da garantia de qualidade e da balança individual do rendimento até nas profundezas do desenvolvimento da primeira infância, as crianças veem-se confrontadas - desde sua experiência consciente da formação - com a submissão de sua ambição de formação à matriz de testes, sendo elas "desde o início" ajustadas às estruturas gerais de funcionamento do campo educacional. ${ }^{31}$ Tal como na análise da estrutura repressiva de necessidades, feita por Marcuse, já se encontra no desejo ajustado uma forma de submissão, ${ }^{32}$ a motivação para a formação dirigida, desde o início, à estrutura de teste entrega-se a esse gesto repressivo. Se alunos mostram interesse 
em determinados conteúdos de ensino única e exclusivamente quando esses são relevantes para exames centrais ou outros, ou se, na aula inaugural de um curso, os estudantes mostram muito mais interesse nas exigências com vista ao exame e aos estudos do que na feição do conteúdo do curso, têm-se aí os primeiros frutos de um desenvolvimento, cujo andamento ainda não é previsível, ainda que sua direção assuma contornos cada vez mais claros.

Quando Marcuse fala de um aplainamento da contradição entre necessidades individuais e sociais ao tratar-se da estrutura de necessidade, é possível constatar, no campo educativo, um aplainamento análogo da oposição entre motivações intrínsecas e extrínsecas à formação. Uma vez internalizadas as motivações extrínsecas, tais como procedimentos de exame e teste, desde a primeira infância, elas se transformam, passo a passo, em motivações intrínsecas, fazendo com que motivações diferentes, autonomamente criadas e originadas no próprio sujeito de formação, cheguem a sucumbir. Porém, o alcance das consequências de tal desenvolvimento ficará visível somente quando levarmos em consideração a relatada focagem do conteúdo nos procedimentos de teste. Uma vez excluídas dos procedimentos de teste, as competências estéticas, emocionais e sociais, devido à falta (ou apenas precariedade) de sua operacionalidade, perdem não apenas a relevância objetiva, senão, antes de tudo, a subjetiva.

Ora, não é apenas em relação ao aspecto motivacional que os indivíduos vêm sendo ajustados; o ajuste refere-se também aos conteúdos da formação. Forçada com o Pisa, a focagem na competência de fazer leituras assim como nas competências em ciências naturais e matemática colocará aquelas disciplinas que visam a habilidades artísticas, emocionais e sociais mais ainda para o segundo plano - exatamente diante do mencionado entendimento técnico-pragmático da competência de leitura. Além disso, a orientação disciplinar do conceito de competência, já referida, impede a interlocução extremamente criativa entre tais disciplinas. Como se isso não bastasse, a direção para "a memória disciplinar, o saber abrangente, as habilidades automatizadas", tal como recomendada na perícia de Klieme sobre procedimentos de teste, posterga o trato criativo, autônomo e até renitente dos conteúdos educativos para posições derradeiras. Suspeita-se, com isso (e aí se religam novamente o conteúdo e a motivação), que o significado crescente de tais testes na biografia individual da formação faça secar a fonte criativa, ou seja, faça-a desaparecer na insignificância motivacional.

É exatamente aqui que se observa também a contradição básica dos desenvolvimentos atuais. Por um lado, aspira-se ao ser humano ajustado segundo as demandas econômicas; um ser cujas competências enquanto capital humano são diretamente aproveitáveis e que foi ajustado desde o início a essas demandas e 
diretrizes. Por outro, porém, são exatamente as motivações e paixões autônomas, rebeldes e criativas que tornam essas competências vivas, podendo dar a elas a feição produtiva. Os desenvolvimentos atuais têm, exatamente, na criatividade, emocionalidade e motivação na sua mancha negra, desde que não se leve em consideração que também esses aspectos precisam de desafio e apoio, sem os quais eles passam a atrofiar-se. Com referência aos conteúdos da formação (e, consequentemente, também em relação aos possíveis conteúdos profissionais), o ser humano ajustado com sua memória disciplinar, seu saber abrangente e suas habilidades automatizadas é tendencialmente impassível e não criativo - até abstraindo de seu cunho social. Na tentativa de controlar progressivamente a produção de recursos humanos, corta-se ao próprio recurso, ao capital humano, sua fonte vital.

Essa contradição nos desenvolvimentos atuais ultrapassa, assim, a si mesma, opondo-se, na verdade, às tendências referidas. $\mathrm{O}$ visado homem ajustado, que poderia satisfazer às exigências econômicas, é exatamente aquele que, a partir de si mesmo, é capaz de romper com essas diretrizes; que é, portanto, maior e autônomo, de maneira que consegue por si só refletir e vencer seu próprio ajustamento à medida, sua adequação ao que é dado, no intuito de poder visar, com criatividade, à base da própria motivação e com paixão, algo novo. Tal maioridade - e isso pode ser visto como o aspecto delicado desse desenvolvimento - não é, porém, uma constante antropológica, nem se desenvolve única e exclusivamente devido a impulsos econômicos para maximizar o benefício, ela precisa ser formada, a saber, em espaços abertos que, diante das tendências atuais no campo educacional, vêm sendo progressivamente enterrados.

\section{0"padrão de sociedades livres" - uma perspectiva}

Diante da situação apresentada até aqui, poderia dar esperança o fato de constatar-se, recentemente, um "renascimento da formação", tal como anunciado no título do fascículo temático da Zeitschrift für Pädagogik (v. 4, 2015): "Bildung (formação) - renascimento de uma ideia guia". ${ }^{33}$ Também não deixa de ser significativa a manifestação de oposição às tendências referidas, confirmada por 3.000 assinantes de uma carta escrita por Dieter Meyer e Katie Zahedi e dirigida ao diretor da OECD, Andreas Schleicher; carta essa que discute criticamente os desenvolvimentos resultantes do estudo Pisa. No entanto, pergunta-se se a oposição à concepção absolutista da ideia de educação da OECD e o renascimento do conceito de formação, por si só, já podem servir de padrão alternativo, no sentido de uma "educação para a maioridade", conforme proposto por Adorno. Se, por exemplo, Andreas Dörpinghaus, um representante desse renascimento, coloca também o peso 
de seu conceito de formação numa "abordagem crítica de distanciamento conceitual”, pergunta-se se essa aspiração pela maioridade não segue também uma divisão cognitiva ao meio do conceito de formação. ${ }^{34}$ Nesse mesmo sentido, Heinrich Roth alerta sobre a necessidade de que na concepção da pedagogia da competência, a dimensão afetivo-emocional assuma uma forma autêntica da maioridade, que se expressa para ele no termo "maturidade ${ }^{35}$ No seu escrito tardio Versuch über die Befreiung (Ensaio sobre a libertação), Marcuse vai além, ao constatar que:

[...] a dimensão estética [poderia] servir de um tipo de padrão para uma sociedade livre. [...] Pois as necessidades estéticas têm seu conteúdo social próprio; elas são demandas do organismo humano, do espírito e do corpo em busca de sua satisfação, que só são alcançáveis na luta contra as instituições que, mediante seu funcionamento, negam e ferem essas demandas (MARCUSE, 1969, p. 48).

Nesse sentido, a referência ao significado da dimensão criativo-estética, além do exigido distanciamento crítico-conceitual, pode ser vista como a tarefa mais urgente de um renascimento da formação, que, sobretudo diante das tendências cognitivistas, tem de ser refletida no contexto e em consequência do conceito clássico de formação (Bildung).

Mesmo assim, pergunta-se até que ponto tal renascimento poderá impor-se contra a prepotência dos interesses econômicos que está acompanhando a atual reforma da educação; ou se esse renascimento perde-se no discurso puro da disciplina, fazendo com que o discurso formativo sobre a retomada da aspiração por uma maioridade não dividida pelo meio continue à espera. Seja qual for o futuro desenvolvimento, a avaliação de Heydorn continua valendo sem restrição:

Maioridade entendida como formação realizada precisa suportar a si mesma no processo da história, sendo submissa à sua própria contradição. Na radicalidade do conceito, ela já se vê ratificada, e o ser humano, libertado para si mesmo; porém, seus pés não se livram do calçamento, em cima do qual eles estão pisando (1972, p. 9).

\section{Notas}

1 Tradução do alemão para o português de Hans-Georg Flickinger.

2 Ver Baumert et al. (2001).

3 Sobre a economia de educação da OECD nos anos 1960 e 1970, conferir Myung-Shin-Kim (1994).

4 Para o desenvolvimento posterior até o estudo Pisa, precisa ser mencionado que a essa resolução pertence, entre outros, o fortalecimento das áreas: ciências naturais, matemática e modernas línguas estrangeiras (Título III da resolução: "financial assistance for strengthening Science, mathematics and modern foreign language instruction”), assim como a introdução de procedimentos de teste, para a identificação de talentos especiais (Título V da resolução: "guidance, counseling, and testing, identification and encouragement of able students").

5 "Com os programas de formação profissional visava-se a um objetivo duplo: por um lado, os participantes deveriam familiarizar-se com as teorias e estratégias gerais do planejamento da educação; por outro, a qualificação visava à conformidade dos participantes com as ideologias por trás dessas teorias. O processo de estandardização das políticas educacionais pressupôs agentes nacionais conformes que precisavam ser qualificados com antecedência" (TRÖHLER, 2013, p. 70). 
6 Sobre os departamentos iniciais com referência à educação dentro da OECD, ver Jacobi (2007, p. 166-181).

7 Elas podem ser vistas como "documento antigo", pois um dos clássicos da teoria do capital humano, que constrói também a relação com a educação, foi publicado somente três anos depois: trata-se de Human capital, de Gary S. Becker (1964). Apenas um ensaio de Theodore W. Schultz, de 1960, remete a uma apresentação mais antiga dessa concatenação. Compare, a esse respeito, Theodore W. Schultz (1960, p. 571-583) e Henning Laux (2009, p. 4-15, sobretudo a p. 6).

8 Sobre essa conexão, ver Karl-Heinz Dammer (2015, p. 136).

9 O livro apresenta um resumo das contribuições, a citação, porém, é do ensaio original de Philip H. Coombs.

${ }^{10}$ Neste relatório estatístico, são apresentados e analisados diversos indicadores estatísticos comparados em nível internacional (países da OECD e outros). O relatório de 2015, na versão alemã, tem um volume de 700 páginas.

${ }^{11}$ Sebastian Lerch resume essa troca de princípio como segue: "Ainda que, na teoria clássica, formação em Wilhelm von Humboldt já falasse da formação como processo vitalício, [...] mudara-se a ideia por trás dessa pretensão. O padrão não era mais o ser humano enquanto tal, mas as qualificações exigidas segundo o interesse da sociedade" (LERCH, apud LEDERER, 2015, p. 311).

12 "A reforma estrutural, planejada por ela (a comissão de formação - D.S.), não se realiza sem a reforma da administração educacional; às estruturas novas têm de corresponder formas novas da organização administrativa” (DEUTSCHER BILDUNGSRAT, 1970, p. 253).

${ }_{13}^{13}$ Sobre a crítica dessa avaliação, ver Andreas Gruschka (2007, p. 14).

${ }^{14}$ Sobre a explicação dessa definição na perícia, ver Klieme et al. (2007, p. 72).

${ }^{15}$ Com um olhar crítico dessa concentração em solucionar problemas, ver Wiechmann (2013, p. 124-147).

16 "Na descrição de competência e, sobretudo, nas tentativas de sua operacionalização, prevalecem, antes de tudo, caraterísticas cognitivas (memória disciplinar, conhecimento amplo, habilidades automatizadas). No entanto, pertencem ao conceito de competência também e explicitamente caraterísticas motivacionais e práticas" (KLIEME et al., 2007, p. 72).

${ }^{17}$ Na página posterior, Klieme e Leutner falam explicitamente dessa focalização: "No sentido de uma focalização no conteúdo do SPP, o conceito de competência aí usado reduz-se a dimensões cognitivas" (KLIEME; LEUTNER, 2006, p. 880, grifo dos autores).

18 "As primeiras abordagens de modelagem e análise focalizam, sobretudo, aspectos cognitivos da construção de competência, ao passo que as facetas afetivo-motivacionais e autorreguladoras ainda não são testadas ou recolhidas em separado" (BLÖMKE; ZLATKIN-TROITSCHANKAIA, 2013, p. 4).

${ }^{19}$ A citação no contexto é a seguinte: "Além da habilidade de resolver determinados problemas, essa definição tematiza também a disposição de usar, de fato, essa habilidade. Neste sentido, habilidade e disposição caracterizam o conceito de competência de Weinert, dirigido à ação. Em contrapartida a isso, o programa principal da DFG - assim como os demais programa encaminhados na sua sequência - concentra-se nos aspectos cognitivos das competências. Em última instância, porém, há de se supor que, no momento em que competências são recolhidas via testes, são medidos além dos momentos cognitivos também elementos afetivos" (LEUTNER, 2014, p. 391).

${ }^{20}$ A respeito, Nicht e Müller escrevem: "Primeiro, a teoria de capital humano e as concepções de competência dirigem-se ao mesmo objeto; a saber, às capacidades e habilidades da população. [...] Nisso, elas definem seu objeto sempre como um produto - ou como rendimento de investimentos em capital humano, ou como resultado de processos de aprendizagem -, colocando esse produto num contexto funcional. Segundo, a teoria de capital humano e as concepções de competência concordam que seu objeto seja mensurável e quantificável, sendo acessível, portanto, à pesquisa empírica quantitativa [...]. Terceiro, ambas as maneiras de pensar são abertas à mudança do plano empírico-descritivo para o normativo. Tanto para o indivíduo quanto para a sociedade, elas subpõem uma correlação entre o nível de formação e bem-estar" (NICHT; MÜLLER, 2009, p. 31, grifo dos autores).

21 "Numa comparação dos diferentes países à base das conclusões de formação, supõe-se, porém, que os conhecimentos e habilidades, mediatizados numa determinada área educativa, sejam iguais em cada país. No entanto, a composição das habilidades e dos conhecimentos do capital humano varia fortemente de um país para o outro, dependendo da estrutura da economia e do nível geral do desenvolvimento econômico" (OECD, 2008, p. 31).

22 "A classificação internacional estandardizada das profissões (Isco) oferece mais uma oportunidade de interconectar o output do sistema educacional com o mercado de trabalho. Em última instância, classificações de profissões remetem ao grau do desenvolvimento econômico e à demanda por habilidades e conhecimentos, podendo servir, por isso, de padrão para a demanda geral pela formação" (OECD, 2008, p. 31).

23 "Desde 2009, a versão mais nova, Isco-08, vem sendo usada, por exemplo, na Ảustria; porém, na Alemanha, vale ainda a classificação das profissões da versão do ano 2010, que foi assimilada estreitamente à Isco-08. Além disso, visava-se englobar a classificação nacional no contexto europeu e internacional. Por isso, o desenvolvimento da KIdB 2010 acompanhava a classificação internacional de profissões (Isco-08), 
mas sem adotar simplesmente a Isco-08 e diferencia-la mais profundamente segundo os fins nacionais. Com sua capacidade de adaptar-se à Isco-08, a KIdB alcança a necessária opção para o futuro e também espera-se - sua aceitação geral dos usuários" (BUNDESAGENTUR FÜR ARBEIT, 2011, p. 6).

${ }^{24}$ Giesecke já alertou que a economização da vida pública "[...] e a atual inundação da linguagem pública por conceitos econômicos [...] não partem sempre $d a$ economia, senão de experiências e de estruturas de pensamento mais empresariais do que político-econômicos” (2005, p. 380, grifo do autor).

25 Essa mudança ficaria evidente também no tratamento do pessoal: "A diferença mostra-se na atitude diante do pessoal. É possível tratar os empregados ou como recurso otimizável, ou como parte constitutiva. No primeiro caso, oferecem-se impulsos, estabelecem-se instâncias de controle e fazem-se ameaças de despedida, ao passo que, no segundo caso, se reforça a ética tradicional da autocorreção, reorganizam-se os foros internos de crítica mútua e sublinha-se a concatenação de lealdade e rendimento” (BUDE, 2011, p. 114).

${ }^{26}$ Ver Lenzen (2014, p. 24) e Kühl (2012).

${ }^{27}$ Sobre o tema, ver Gerritsen (2009, p. 27-30).

${ }^{28}$ Compare com Kühl (2012, p. 143).

${ }^{29}$ Quanto à relação do conceito marcusiano de unidimensionalidade com o problema da formação, ver Stederoth (2006, p. 145-162).

30 Sobre o conceito de "dessublimação repressiva", ver Stederoth (1998, p. 99-112).

31 Junto a isso, desvaloriza-se, naturalmente, o "jogo livre": "A valorização maior da elementar tarefa educativa tem como consequência que a aprendizagem acessória das crianças junto ao jogo se desenvolve em direção à aprendizagem de brincadeira. À aprendizagem de brincadeira atribuem-se maiores acompanhamento sistemático e avaliação didática. O jogo livre é importante, porém deve encontrar-se numa relação adequada com as atividades de aprendizagem, planejadas e iniciadas pelos adultos. Como modelo de aprendizagem, é essencial a vivência cotidiana de situações estruturadas" (KULTUS; SOZIALMINISTERIUM, 2012, p. 31).

32 Segundo Erich Ribolits, trata-se, nessa tendência, “[...] de desenvolver uma personalidade que se define mediante sua utilidade, isto é, de seres humanos que conseguem perceber-se somente na mira de seu valor de mercado e, por isso, não reclamam para si uma dignidade humana dada por princípio, de seres humanos que podem (e querem) sentir-se - em dependência de seu sucesso profissional-material - apenas como mais ou menos 'plenos de valor"' (2009, p. 27, grifo do autor).

33 "O alcance da satisfação socialmente aceitada e desejada está aumentando consideravelmente; porém, no caminho dessa satisfação, reduz-se o princípio de prazer - roubado de suas reivindicações incompatíveis com a sociedade existente. Assimilado desse modo, o prazer cria submissão" (MARCUSE, 1970, p. 95).

${ }^{34}$ Ver, especialmente, a contribuição de Sander (2015, p. 517-526). Vale também mencionar, nesse contexto, que a revista Erwägen, Wissen, Ethik dedicou, um ano antes, uma edição inteira ao tema Bildung. Cabe destacar o editorial de Krassimir Stojanov (2014, p. 203-212), assim como os ricos comentários referentes a esse artigo.

35 Ver Dörpinghaus (2015, p. 464-480).

36 "Maioridade referida única e exclusivamente a rendimentos cognitivos não pode descrever nenhum objetivo educativo capaz de abranger todas as áreas da personalidade e do apreender. O que significa maioridade no campo emocional, afetivo e motivacional? E óbvio que, visto em termos da linguagem, o critério da maturidade remete a essas outras variáveis da personalidade. Se, para assim dizer, produtividade e capacidade crítica representam o lado cognitivo da maioridade, então se entende com a maturidade o lado emocional-afetivo da maioridade" (ROTH et al., 1971, p. 183).

\section{Referências}

BAUMERT, Jürgen et al. (Org.). PISA 2000. Basiskompetenzen von Schülerinnen und Schülern im internationalen Vergleich. Opladen: Leske \& Budrich, 2001.

BECKER, Gary. Human capital: a theoretical and empirical analysis with especial reference to education. Chicago: University Chicago Press, 1964.

BMBF (Org.). Investitionsgut Bildung. Workshop, Investitionen in Humankapital, 7 Juni 2004. Bonn; Berlim: BMBF, 2004. p. 18-21. 
BLÖMKE, Sigrid; ZLATKIN-TROITSCHANKAIA, Olga. Kompetenzmodellierung und Kompetenzerfassung im Hochschulsektor. Ziele, theoretischer Rahmen, Design und Herausforderungen des BMBF- Forschungsprogramms KokoHs. KoKoHs Working Papers 1. Berlim; Mainz: Humboldt University \& Johannes Gutenberg University, 2013.

BRINGOLF, Walter et al. (Org.). Wirtschaftswachstum und Bildungsaufwand. Viena; Frankfurt; Zurique: [s.n.], 1966.

BUDE, Heinz. Bildungspolitik. Was unsere Gesellschaft spaltet. Munique: Carl Hanser, 2011.

BUNDESAGENTUR FÜR ARBEIT. Klassifikation der Berufe 2010. Nuremberg: KLDB, , 2011. (zuei Bände).

DAMMER, Karl-Heinz. Vermessene Bildungsforschung. Wissenschaftsgeschichtliche Hintergründe zu einem neoliberalen Herrschaftsinstrument. Baltmannsweiler: Schneider Verlag Hohengehren, 2015.

DEUTSCHER BIILDUNGSRAT. Strukturplan für das Bildungswesen. Stuttgart: [s.n.], 1970.

DÖRPINGHAUS, Andras. Theorie der Bildung. Versuch einer 'unzureichenden' Grundlegung. Zeitschrift für Pädagogik, h. 4, p. 464-480, 2015.

GERRITSEN, Christian W. A. Kreditpunkte als Parameter für die interne Mittelsteuerung an der Universität von Amsterdam. In: JAEGER, Michael; SANDERS, Sandra (Org.). Modularisierung und Hochschulsteuerung - Ansätze modulbezogenen Monitorings. Dokumentation zur HISTagung am 29. Mai 2009 in Hannover. Hannover: HIS, 2009. p. 27-30.

GIESECKE, Hermann. Humankapital als Bildungsziel? Grenzen ökonomischen Denkens für das pädagogische Handel. Neue Sammlung, h. 3, p. 377-389, 2005.

GRUSCHKA, Andreas. Bildungsstandards oder das Versprechen, Bildungstheorie in empirische Bildungsforschung aufzuheben. In: PONGRATZ, Ludwig A. et al. (Org.). Bildung - Wissen Kompetenz. Bielefeld: Janus Presse, 2007. p. 9-29.

HEYDORN, Heinz-Joachim. Zu einer Neufassung des Bildungsbegriffs. Frankfurt am Main: Suhrkamp, 1972.

JACOBI, Anja P. Die Bildungspolitik der OECD. Vom Erfolg eines scheinbar machtlosen Akteurs. Zeitschrift für Pädagogik, n. 53, h. 2, p. 166-181, 2007.

KLIEME, Eckhard et al. Zur Entwicklung nationaler Bildungsstandards. Expertise. Bonn; Berlim: DIPF, 2007.

KLIEME, Eckard; LEUTNER, Detlev. Kompetenz modelle zur Erfassung individueller: Lernergebnisse und zur Bilanzierung von Bildungsprozessen. Beschreibung eines neu eingerichteten Schwerpunktprogramms der DFG. Zeitschrift für Pädagogik, n. 52, h. 6, S. 876903, 2006.

KÜHL, Stefan. Der Sudoku-Effekt: Hochschulen im Teufelskreis der Bürokratie, Eine Streitschrift. Bielefeld: Science Studies, 2012.

KULTUS. SOZIALMINISTERIUM HESSEN (Org.). Bildung von Anfang an Bildungs und Erziehungsplanung für Kinder von 0 bis 10 Jahren in Hessen. 4. ed. Wiesbaden: GmbH, 2012. 
LAUX, Henning. Die Fabrikation von Humankapital. Eine praxistheoretische Analyse. Berliner Debatte Initial, n. 20, h. 3, p. 04-15, 2009.

LEDERER, Bernd. Kompetenz oder Bildung. Eine Analyse jüngerer Konnotationsverschiebungen des Bildungsbegriffs und Pladoyer für eine Rück- und Neubesinnung auf ein transinstrumentelles Bildungsverständnis. Hamburgo: Tredition, 2015.

LENZEN, Dieter. Bildung statt Bologna. Berlim: Ullstein, 2014.

LEUTNER, Detlef. Möglichkeiten und Grenzen der Kompetenzerfassung. In: BMBF (Org.). Bildungsforschung 2020. Herausforderungen und Perspektiven. Dokumentation der Tagung des Bundesministeriums für Bildung und Forschung von 29 e 30 März. Berlim: BMBF , 2014.

MARCUSE, Herbert. Versuch über die Befreiung. Frankfurt: Suhrkamp, 1969.

MARCUSE, Herbert. Der eindimensionale Mensch. Berlim: Neuwied, 1970.

MESSNER, Rudolf. Das Bildungskonzept von PISA als Teil einer globalen gesellschaftlichen Neuorientierung. In: Erziehung und Unterricht. Österreichische Pädagogische Zeitschrift 7-8, 2000, p. 841-848.

MYUNG-SHIN-KIM. Bildungsökonomie und Bildungsreform: Der Beitrag der OECD in den 60er und 70ger Jahren. Würzburg: Königshausen und Neumann,1994.

NICHT, Jörg; MÜLLER Thomas. Kompetenzen als Humankapital. Über dieWahlverwandtschaft zweier Leitkonzepte zeitgenössischer Bildungsreform. Berliner Debatte Inicial, n. 20, h. 3, p. 30-44, 2009 .

OECD. Bildung auf einen Blick: OECD- Indikatoren. Paris: OECD, 2008.

OECD. Schulen und Qualität. Ein internationaler OECD-Bericht. Frankfurt: OECD, 1991.

RIBOLITS, Erich. Bildung ohne Wert. Wider die Humankapitalisierung des Menschen. Viena: Löcker, 2009.

ROTH, Heinrich et al. Pädagogische Anthropologie, Band II. Entwicklung und Erziehung. Grundlagen einer Entwicklungspädagogik. Hannover: Schroedel, 1971.

SANDER, Wolfgang. Was heißt Renaissance der Bildung? Ein Kommentar. Zeitschrift für Pädagogik, n. 61, h. 4, p. 517-526, 2015.

SCHULTZ, Theodore W. Capital Formation by Education. Journal of Political Economy, n. 68, h. 6 , p. 571-583, 1960.

STEDEROTH, Dirk. Der Begriff der repressiven Entsublimierung bei Herbert Marcuse. In: FLICKINGER, Hans-Georg; MÜLLER, Ulrich (Org.). Über den Umgang mit Macht, Autorität, Institution. Für Wolfram Burisch. Kassel: Brochiert, 1998. n. 34. p. 99-112.

STEDEROTH, Dirk. Bildung aus der Eindimensionalität. Herbert Marcuses Beitrag zu einer kritischen Bildungstheorie. In: EIDAM, Heinz; HOYER, Timo (Org.). Erziehung und Mündigkeit. Bildungsphilosophische Studien. Berlim: Lit, 2006. p. 145-162.

TENORTH, Heinz-Elmar. Bildung: Thematisierungsformen und Bedeutung in der Erziehungswissenschaft. Zeitschrift für Pädagogik, ag. 43, h. 6, p. 970, 1997. 
TRÖHLER, Daniel. Standardisierung nationaler Bildungspolitiken: die Erschaffung Internationaler Experten, Planer und Statistiken in der Frühphase der OECD. IJH Bildungsgeschichte, 3, 1, p. 60-77, 2013.

WEINERT, Franz E. (Org.). Leistungsmessungen in Schulen. Weinheim; Basel: Beltz, 2001.

WIECHMANN, Ralf. Zur Verabsolutierung des Problemlösens im Kompetenzkonzept und ihren Folgen. Vierteljahresschrift für wissenschaftliche Pädagogik, v. 89, h.1, p. 124-147, 2013. 